\title{
The Method of Determination and Detection of Abnormal States in a GT8C Turbine
}

\author{
Konrad STEFANOWICZ, Błażej BAŁASZ, Dariusz LIPIŃSKI, Grzegorz WŁAŻEWSKI
}

\begin{abstract}
The paper describes a new method of determining abnormal states and the way they are detected on GT8C turbine. The system of dividing measured parameters into three groups has been suggested. The paper puts the emphasis on the issue of identifying relevant information contained in the data set. Properties of the GT8C have been given. The significance of monitoring the essential operating parameters has been noted. The steps leading towards the detection of anomalies related to the measured parameter have been made. The tool in form of the method for determining abnormal states shows how to easily implement and supplement the supervision over measured parameters of the machine. The use of computer assisted methods dramatically accelerates the analysis of basic components of the measured parameters thus facilitating the possibilities of detecting the abnormal state of the machine and making a decision on the response.
\end{abstract}

Keywords: control chart patterns; gas turbine; pattern recognition; prediction

\section{INTRODUCTION}

The GT8C gas turbine which is a part of a combined cycle power plant (sBGP) operates at PGE Energia Ciepła S. A. Oddział Elektrociepłownia w Gorzowie Wielkopolskim (ECG). The turbine works together with a recovery boiler $(\mathrm{KO})$. The steam generated in the recovery boiler can supply steam turbine.

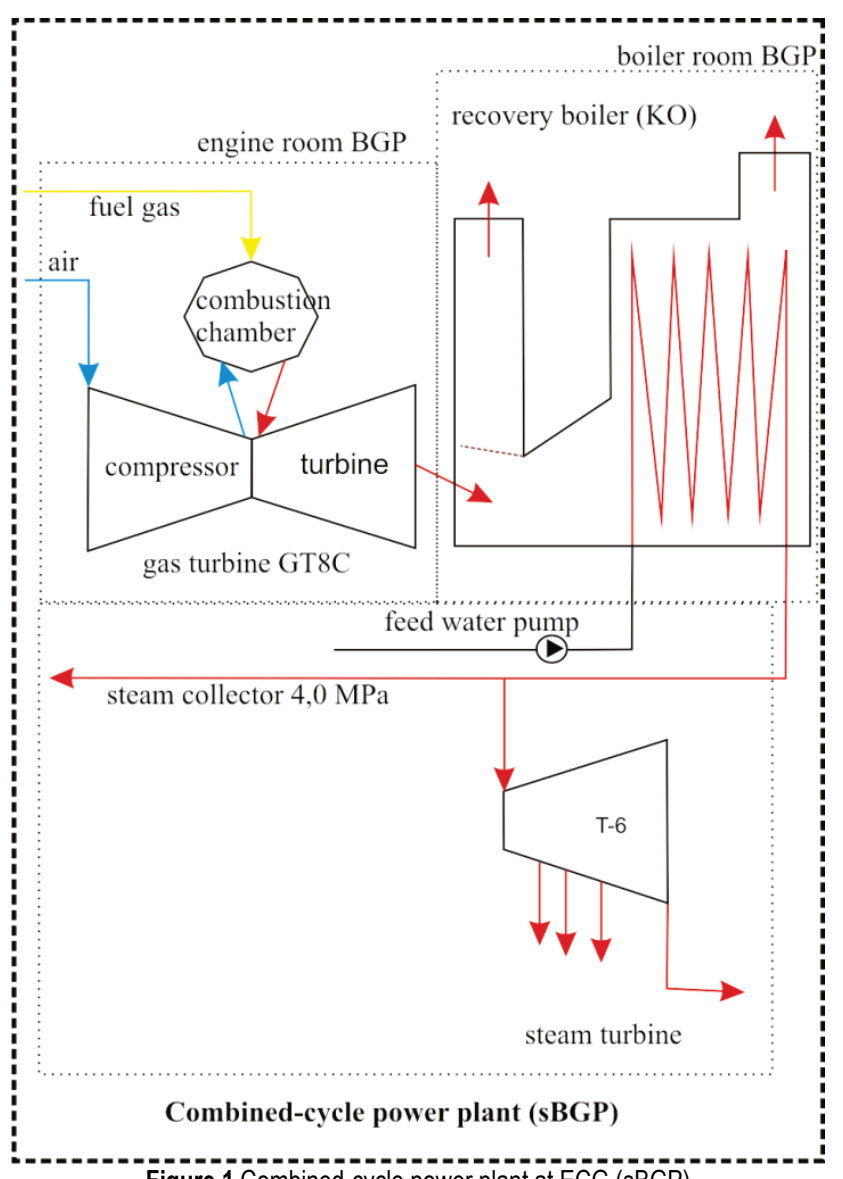

Figure 1 Combined-cycle power plant at ECG (sBGP)

The sBGP operating system is quite complex which makes the operation of machinery and devices rather complicated. Thus, the constant supervision over the operation control is necessary. The attention shall be paid to parameters of the power production values. The values of the parameters shall be monitored and any deviations therefrom need responding thereto $[5,6,8]$. The constant monitoring is required. It is not easy due to a great number of monitored values. An operator makes a choice in state of limited possibilities of displaying trends (monitored values) on one or several screens. The operator has to make decisions regarding the choice of parameters on the basis of his/her experience and knowledge.

The constant monitoring of a machine state can prevent the machine from serious failure and huge breakdown cost [9].

\section{DESCRIPTION OF DAMAGE SUFFERED DUE TO FAILURE}

A serious failure which occurred in 2008 resulted, among other things, in the damage to blades of the second stage.

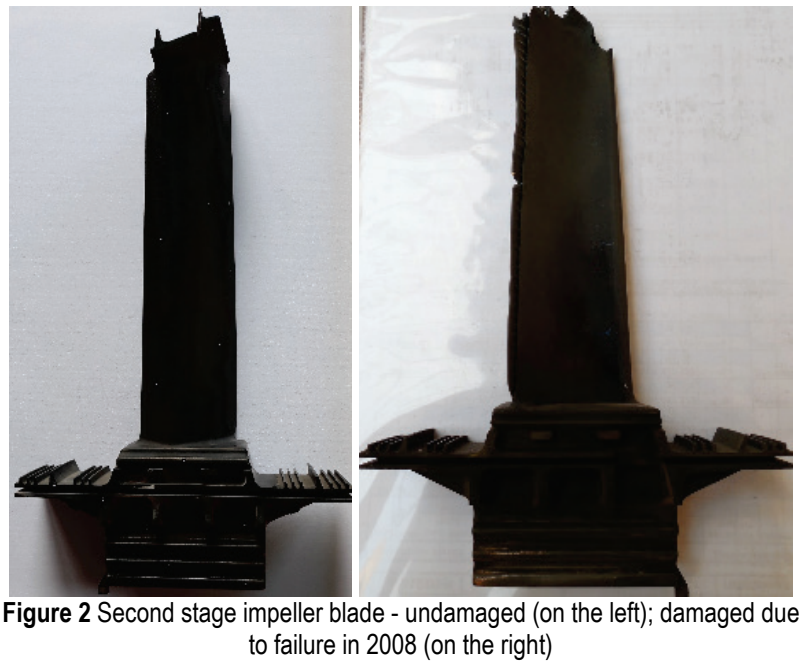

The above figure shows that a serious damage to main components of the machine, and even a complete shutdown of the machine, can result out of a failure to identify symptoms received from the monitored values in time.

Spots of the damaged areas were checked by Atos Triple Scan 3-D scanner of GOM.

First of all, a model of an undamaged impeller blade of the second stage was made on the basis of the gathered 
cloud of points. The next step was gathering a cloud of points of the damaged blade of the second stage. A preliminary referencing of the model and the clouds of points with a deviation of $0.22 \mathrm{~mm}$ was achieved.

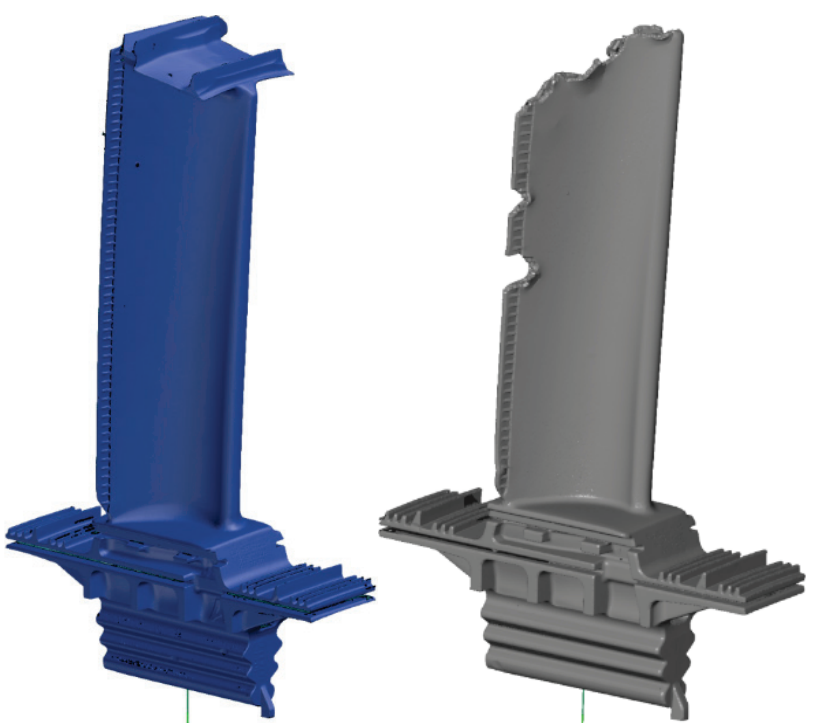

Figure 3 Second stage impeller blade (on the left - a model of undamaged blade; on the right - a cloud of points of a damaged second stage impeller blade)

They were superimposed and shown in Fig. 3 which makes it possible to evaluate the scale of damage to the working part of the GT8C.

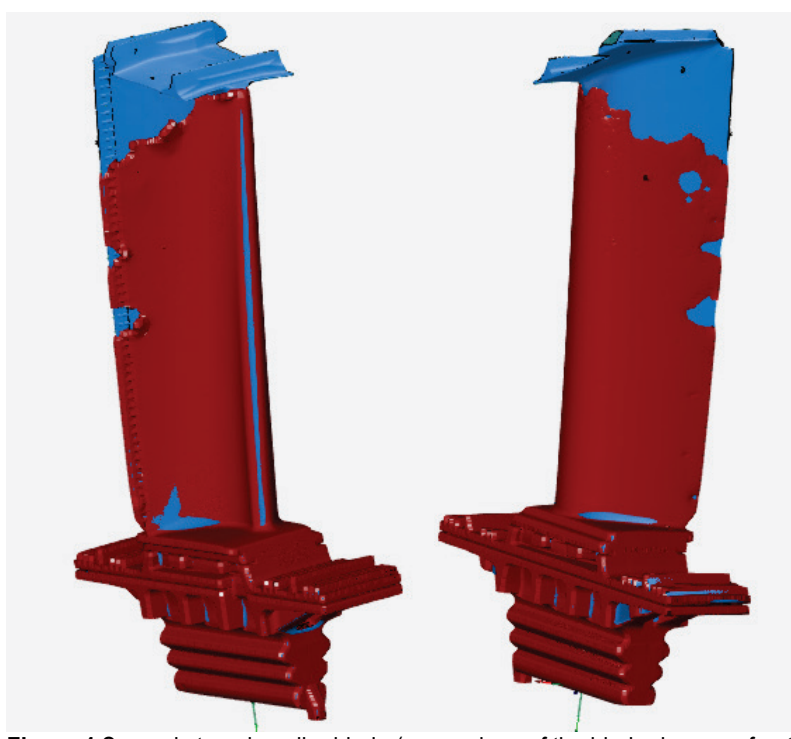

Figure 4 Second stage impeller blade (comparison of the blade damage, front view - on the left; comparison of the blade damage - rear view - on the right)

The upper part of the blade with sealing elements, the so called knives, which were to cut grooves in the honeycomb, were damaged. Spots damaged by hitting with fragments of torn off pieces were represented on the gathered clouds of the points. The preliminary comparison with a surface of the undamaged blade model of the second stage shows characteristic spots of the damage.

It can be observed that the deformation following the damage ran along a tip of the blade profile, where the blade section area is the smallest and weakest (due to cooling air outlet holes).

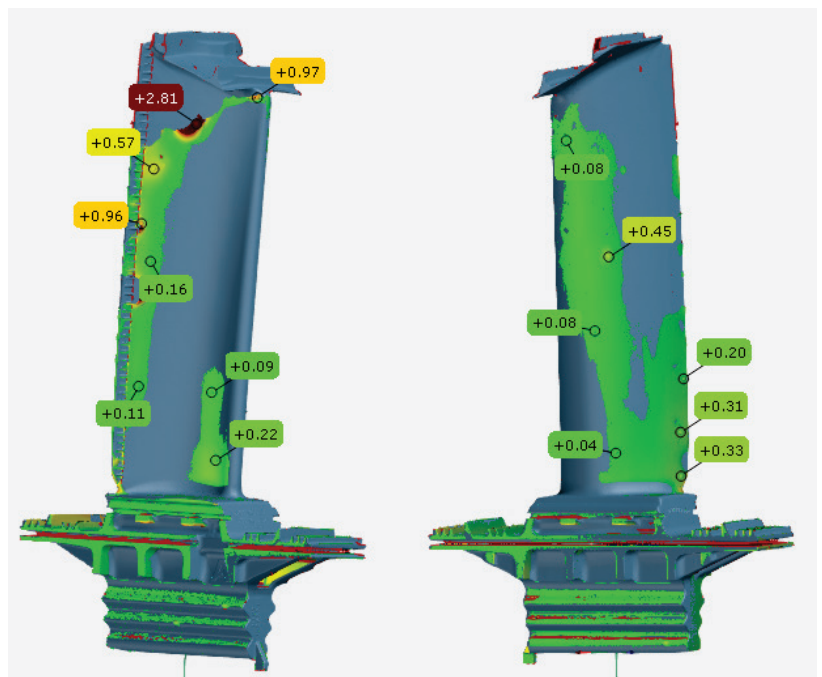

Figure 5 Second stage impeller blade (comparison of the surface, front view on the left; comparison of the surface - rear view - on the right)

\section{MEASURED PARAMETERS OF THE GT8C}

The GT8C is a single shaft turbine of the rated output of 54.5 MW. The main parts of the gas turbine are as follows: 3-stage gas turbine GT8 (incl. of two cooled stages), 12-stage compressor, one silo-type combustion chamber with 19 low $\mathrm{NO}_{x}$ burners type EV. The gear changes the turbine shaft speed of $6209 \mathrm{rpm}$ to $3000 \mathrm{rpm}$ [3].

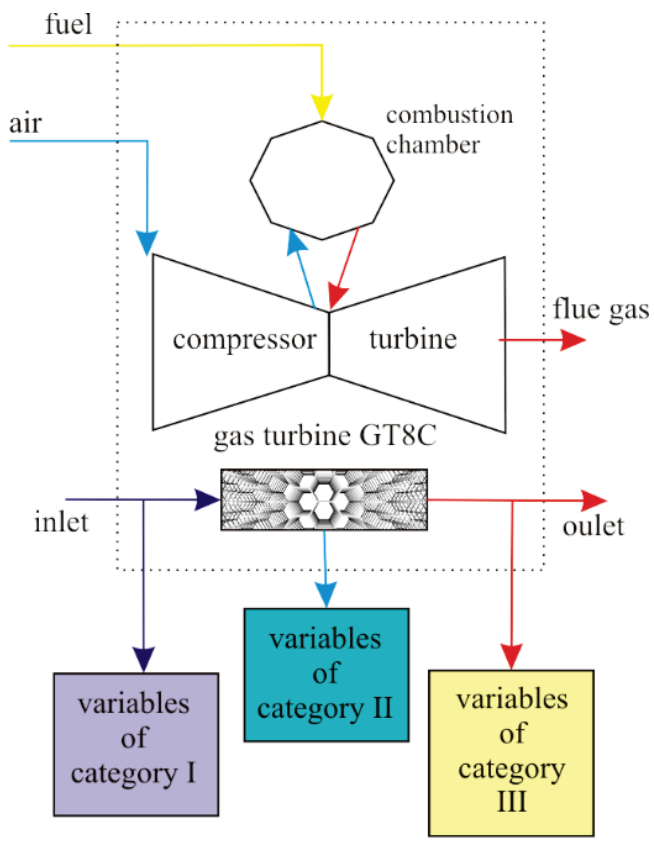

Figure 6 Division of the measured parameters, gas turbine GT8C

The GT8C drives a generator of the active power of 59.04 MW through a gear. The air is supplied to the compressor from the air intake equipped with a 2-stage filter with Pre-filters class M6 and end filters class F7. The fuel is a high nitrogen content gas supplied by Kopalnia Ropy Naftoweji Gazu Ziemnego Dębno - PGNiG S.A.

Auxiliary systems supporting the operation of the GT8C are as follows:

- $\quad$ oil system comprising lubricating oil tanks (main and secondary tanks), oil mist ex-tractor fan, lubricating oil 
main pump, double oil filter, oil plate cooler, secondary oil pump, emergency oil pump;

- jacking oil pump comprising: oil tank, oil pump, oil filter, oil cooler;

- gas control system;

- $\quad$ shut-off valves system;

- $\quad$ bearing support cooling system (flue gas outlet);

- compressor blowdown system;

- compressor wash system.

The GT8C can be divided into components according to its design and structure. The diagram below shows the basic division of the measured parameters.

Variables of category I measures input parameters of the GT8C. They cover such items, as ambient air temperature of fuel (gas) amount. Variables of category II include measured parameters of the GT8C. The parameters concerned are, for instance, bearing No. 1 vibration propagation, or bearing metal temperature. Variables of category III comprise output measured parameters of the GT8C, e.g. outlet flue gas temperature.

The measured parameters contain several components such as:

1. information on the state

2. information on the value

3. information on the quantity

4. information on the significance of a property

The amount of the information is huge. It makes displaying the information in form of trends very difficult and crucial information can be blurred and thus certainly omitted. The key issue is to identify the right information in the database. The amount of the information is becoming even more important in case of a greater number of machines installed.

A characteristic property of each rotating machine is a speed of vibration of the shaft bearing housing [7]. In case of the GT8C, turbine stages and compressor stages are situated on one shaft. The vibration speed is measured on the housing facing the turbine, i.e. hot bearing No. 1: signal KKS 08MBD10CY001.XQ01, and on the housing facing the compressor, bearing No. 2: signal KKS 08MBD20CY001.XQ01.

Because of the silo-type combustion chamber the additional characteristic property of the turbine is also a speed of the combustion chamber housing vibration; signal KKS 08MBM30CY001.XQ01.

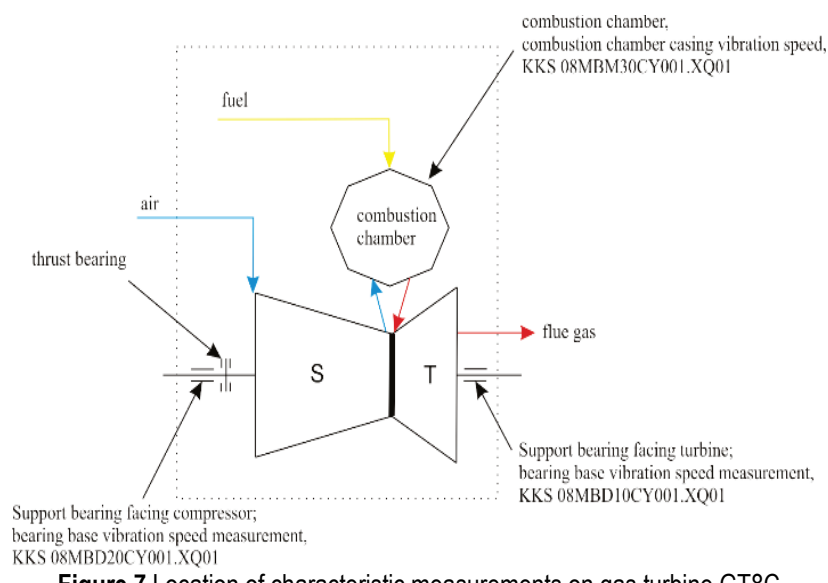

Figure 7 Location of characteristic measurements on gas turbine GT8C
The above diagram lays grounds for concluding that the three properties might contain the information on the dynamic state of the machine in a given time. Some additional properties, such as temperature, power, efficiency, can be distinguished as well.

\section{NEED FOR MONITORING THE PARAMETERS}

Key parameters of the machine shall be monitored in order to provide the correct and safe operation. Operators on duty check certain selected parameters. They take advantage of the visualization systems designed for the production parameters and machine operation ones, as shown in Fig. 8 [2].

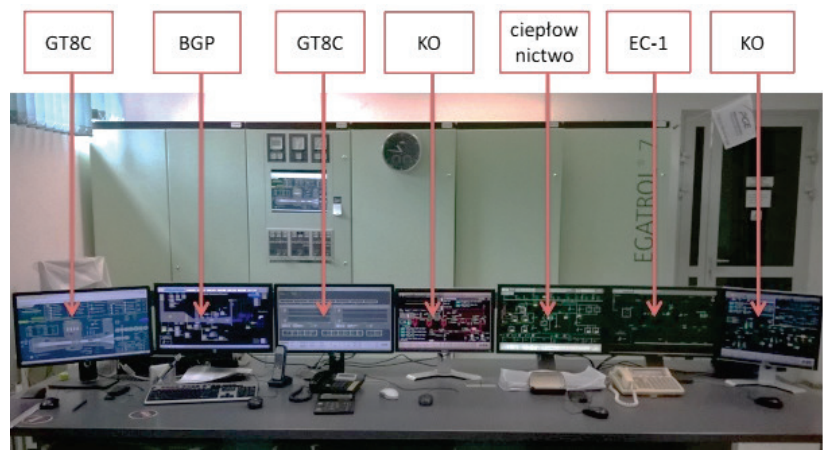

Figure 8 CCPP control room with several screens at ECG in 2016

The machine operators can display parameters change trends in real time and follow the trend changes.

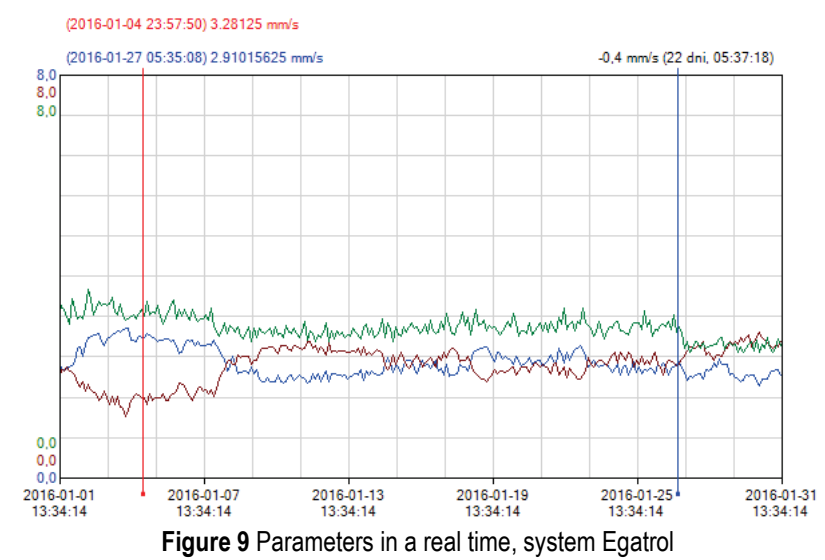

It is impossible to visualize all the parameters of the machine and equipment and that is why the operators periodically check them on site. Certain machine parameters are provided with alarms that represent the actual status. For instance, KKS 08MBD10CY001.XQ01 (vibration speed of bearing No. 1 of the GT8C) is provided with the following alarm thresholds:

1. First level $-7.00 \mathrm{~mm} / \mathrm{s}$ - alarm

2. Second level $-18.00 \mathrm{~mm} / \mathrm{s}$ - turbine trip

It is quite troublesome that the signal which is within alarm limits is not monitored.

The key issue which is quite often neglected is the need for monitoring parameters to maintain the assets. Maintaining the assets is connected with performing the maintenance, planned and current repair activities are aimed at resuming the rated parameters of the machine. 


\section{PERIOD BETWEEN OVERHAULS}

Periods between overhauls have been established by turbine manufacturer. The periods take into consideration the machine operating conditions. Certain categories of the overhaul cover different ranges of the work involved. Inspection type " $A$ " is the minimum inspection during which the visual check of the turbine is performed. Inspection type " $B$ " covers the range of the " $A$ " and additionally includes the check of auxiliary systems. Inspection type " $C$ " is the main overhaul that covers the replacement of main components of the turbine. The " $C$ " requires dismantling of the top casing and top intermediate casings of turbine components [1].

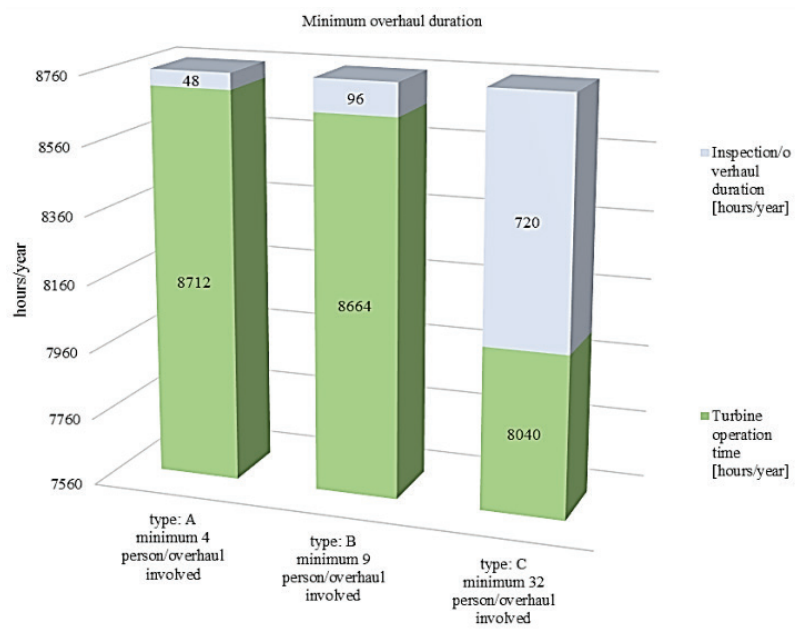

Figure 10 Inspection/overhaul duration

The assumed range of the inspection and overhaul is connected with the duration as shown in Fig. 10 and recommended number of the staff having relevant skills and qualifications. The time-schedule of overhauls was designed with regard to the equivalent operating hours $(\mathrm{EOH})$. The service life of $8000 \mathrm{EOH}$ between inspections/overhauls was adopted. It means the turbine would run $24000 \mathrm{EOH}$ between the " $C$ " overhauls.

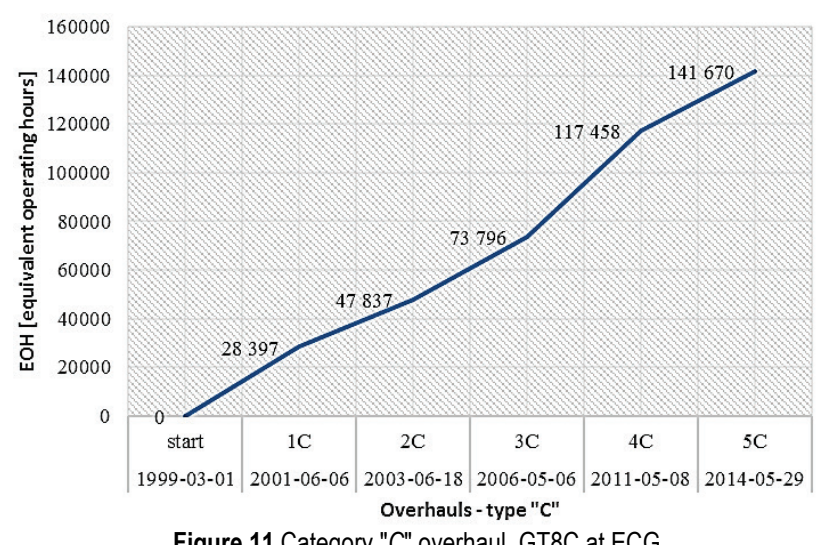

\section{DATA SET}

Values of the measured parameters are stored. The values are continually collected. A sampling interval is 1 second. As of today there are 428 basic parameters of the GT8C. They are divided into two groups with regard to the nature of the signal, i.e.; analogue and discrete signals. There are 268 analogue parameters and 160 discrete ones accordingly.

A selected parameter can be viewed during the operation of the GT8C. The parameter can be configured on a curve in any time interval. Fig. 12 shows changes to a parameter within one month.

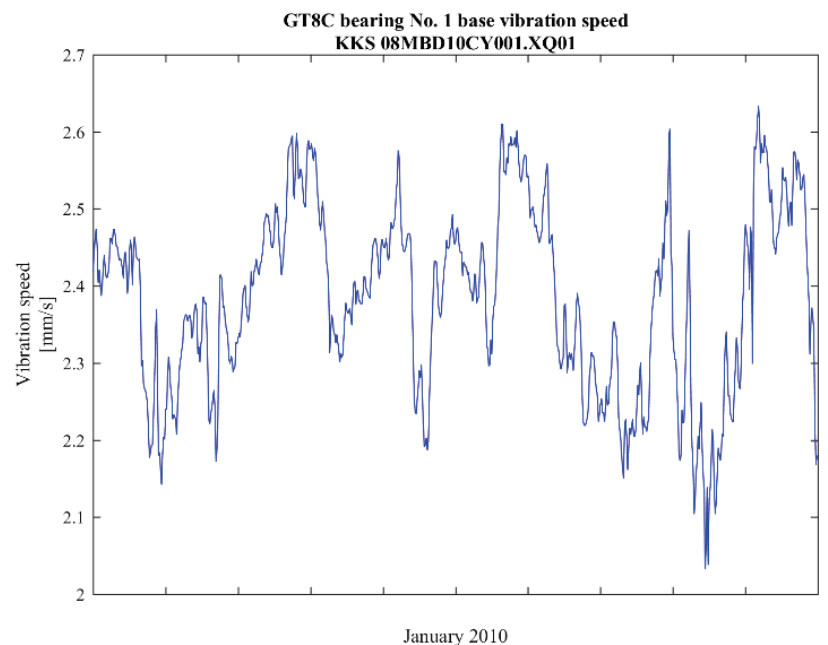

Figure 12 Bearing No. 1 base vibration speed, January 2010

The average hour values of the signal were calculated for a selected monthly measurement of the parameter. The values were aggregated in daily groups and shown in Fig. 13 .

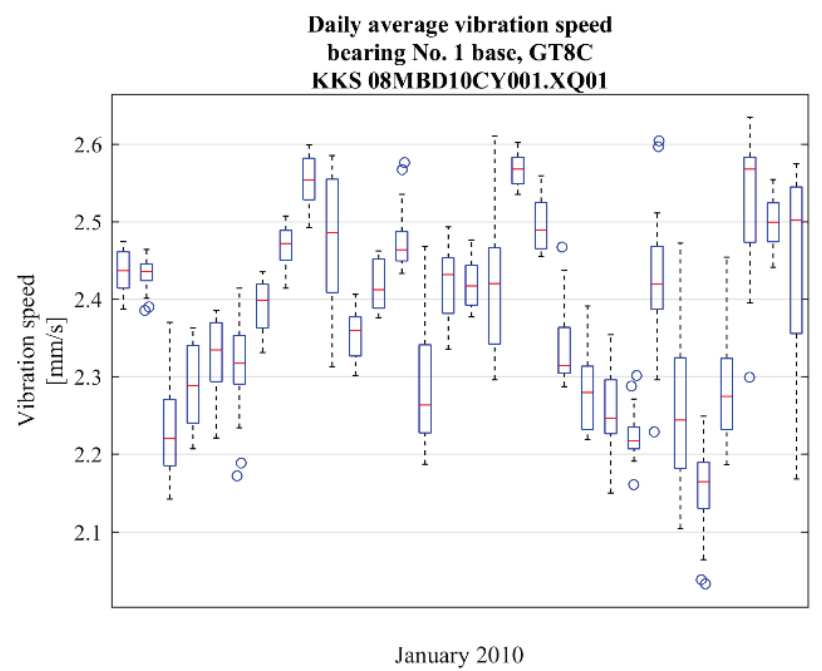

Figure 13 Daily average, bearing No. 1 base, vibration speed, January 2010

All measured parameters of the GT8C were gathered to help find a tool for the identification of abnormal states.

First step to identify the abnormal states was the analysis of the parameters in form of curves. The equal signal level can be observed while representing the selected parameters over a long time interval. The example of the vibration speed signal is shown in Fig. 14.

Another example is shown in Fig. 15 where changes to the parameter level - anomalies. Red lines in Fig. 15 mark the confidence interval for the values observed. The span of the confidence interval is $95 \%$ statistics $z$ of the normal distribution for a certain confidence level $(1-\alpha) 100 \%$, for $95 \%$ confidence interval $z_{\alpha / 2}=1.96$. 
Changes to the signal level can be noticed in different operation periods of the GT8C while comparing the parameters. In 2010 the curve representing the vibration speed of bearing No. 1 base, from January through May, signal KKS 08MBD10CY001.XQ01, showed the equal level in Fig. 14. The same signal departed from the average in May 2008. The deviation exceeded both the top limit of the confidence interval as well as the bottom limit shown in Fig. 15.

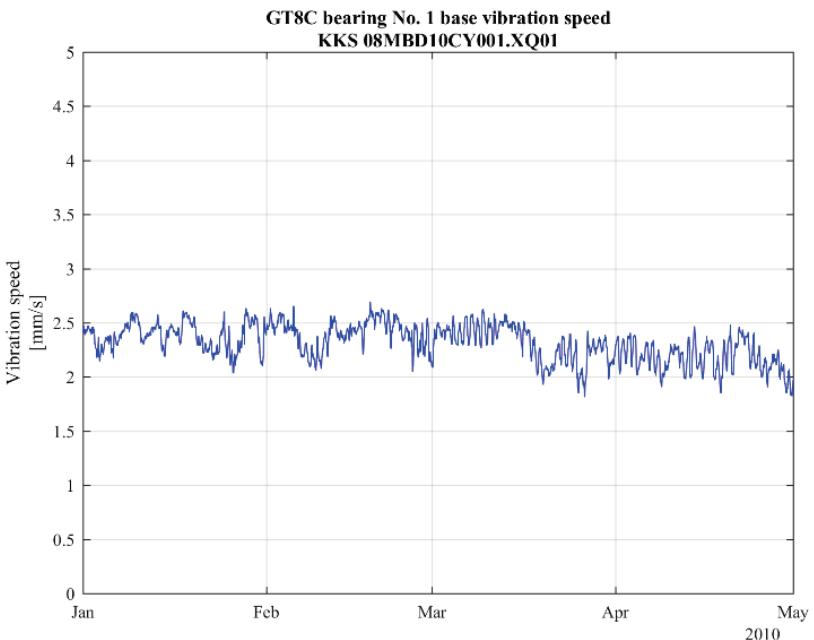

Figure 14 Bearing No. 1 base vibration speed, GT8C, January-May 2010

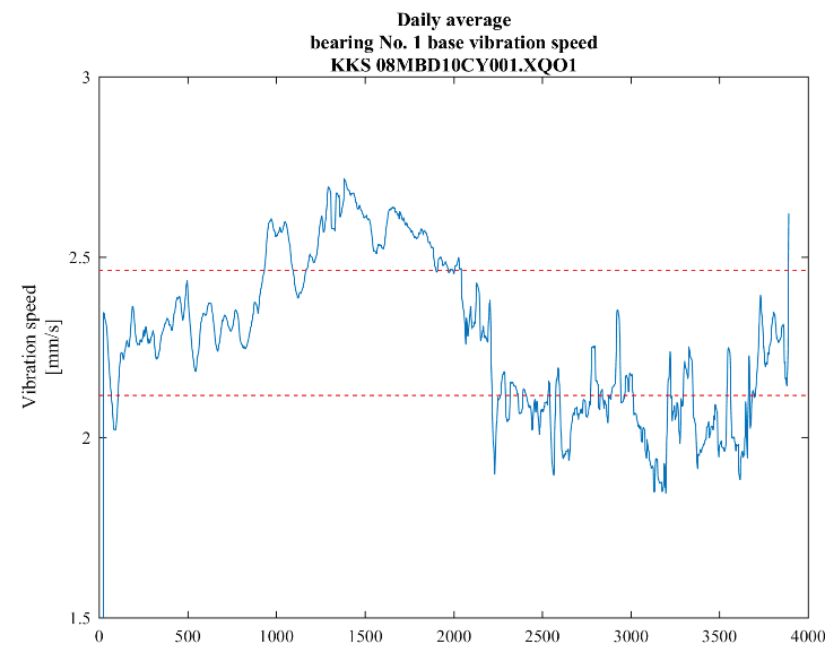

Figure 15 Daily average, bearing No. 1 base vibration speed, GT8C, before inspection_P0

To spot anomalies on the curve can be the first step to further watch the parameter, and consequently to make decisions on the operation of the machine.

\section{DETECTING THE ANOMALIES}

The first step to look for anomalies on the basis of selected properties is to establish an interval of the typical values of the parameter.

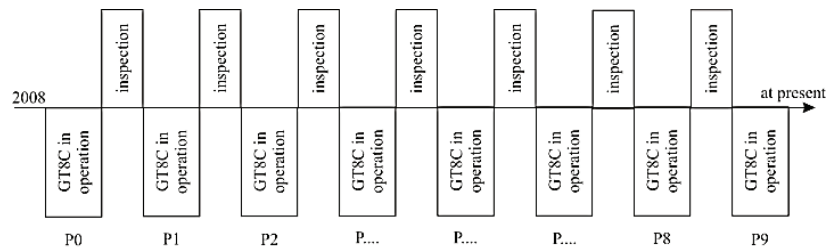

Figure 16 Machine operation intervals between shut-downs, 2008-2016
The typical properties are the ones that do not exceed interval limits over the set period shown in Fig. 16.

To develop a method, the signal of vibration speed of bearing No. 1 base, KKS 08MBD10CY001.XQ01, was systematized into hourly average samples. The samples were listed in the machine operation intervals [4].

The average value and the value of the standard deviation were calculated for a 720 -hour interval. The 720 hour interval was adopted according to the expertise available as the most representative due to the monthly repeatability of the operation activities performed on the machine. Then the daily average values and the daily standard deviation values over the entire machine operation interval were calculated.

The value of the standard deviation which does not exceed the value of the adopted confidence interval was coloured green - see Fig. 17. Values exceeding the adopted confidence interval were coloured yellow below the adopted confidence interval, and red above the adopted interval respectively - see Fig. 17.

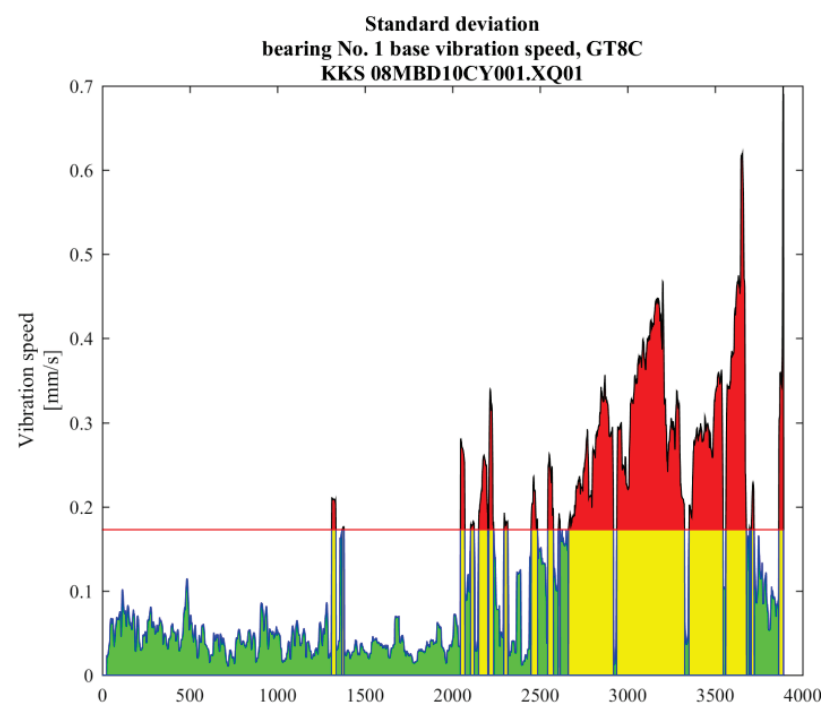

Figure 17 Standard deviation area, bearing No. 1 base vibration speed, GT8C, year 2008_PO

Such approach made it possible to distinguish instantaneous anomalies of the signal in question.

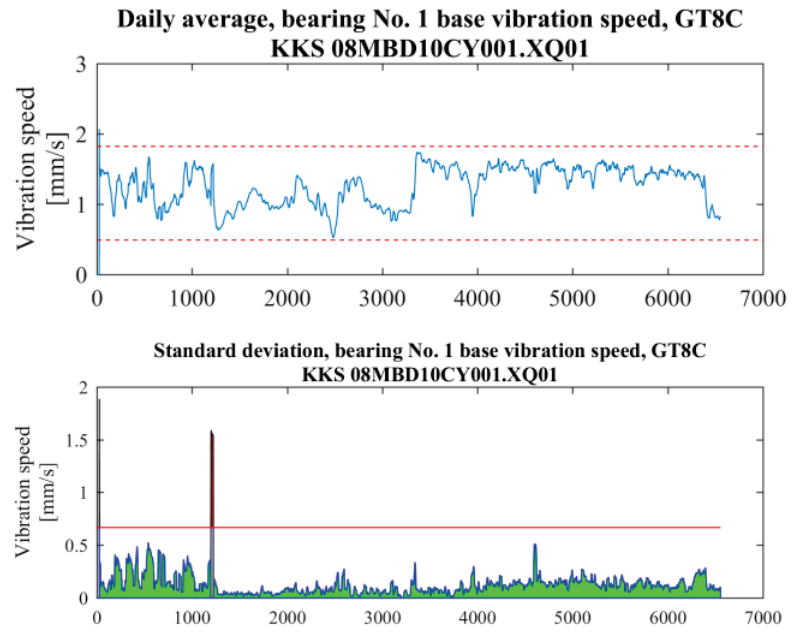

Figure 18 Daily average and standard deviation, bearing No. 1 base vibration speed, year 2008/2009 P1 
Year 2008 was chosen on purpose because of the failure of the GT8C. The comparison of the signal values and more detailed representation of parameters of the tool designed would make it possible to precisely verify the efficiency of the method. The above algorithm was a basis for the analysis of the next years, and results are shown below in Figs. 18 to 26.
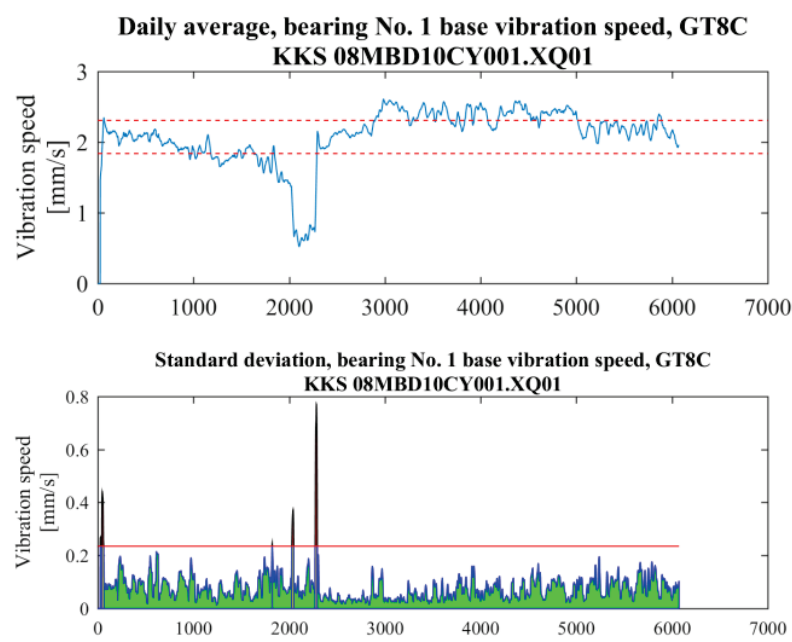

Figure 19 Daily average and standard deviation, bearing No. 1 base vibration speed, year 2009/2010_P2
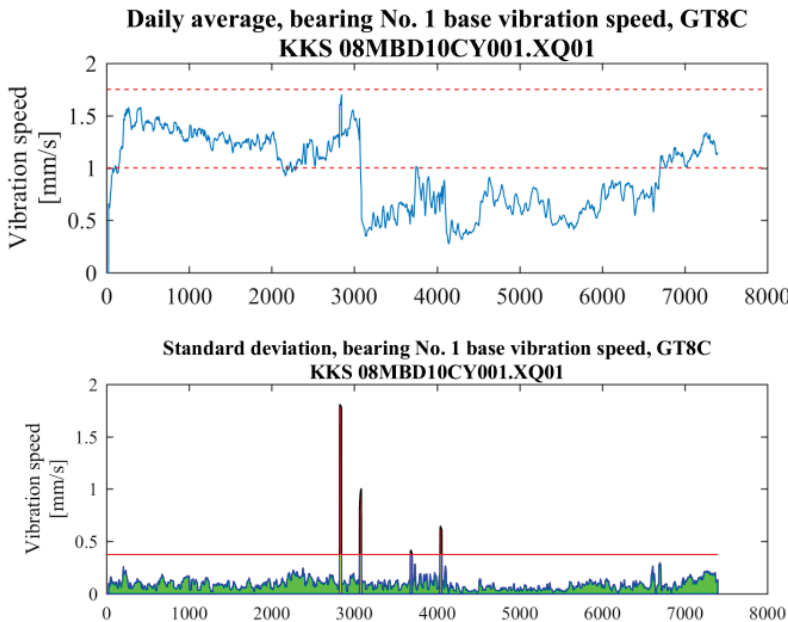

Figure 20 Daily average and standard deviation, bearing No. 1 base vibration speed, year 2010/2011_P3

Daily average, bearing No. 1 base vibration speed, GT8C
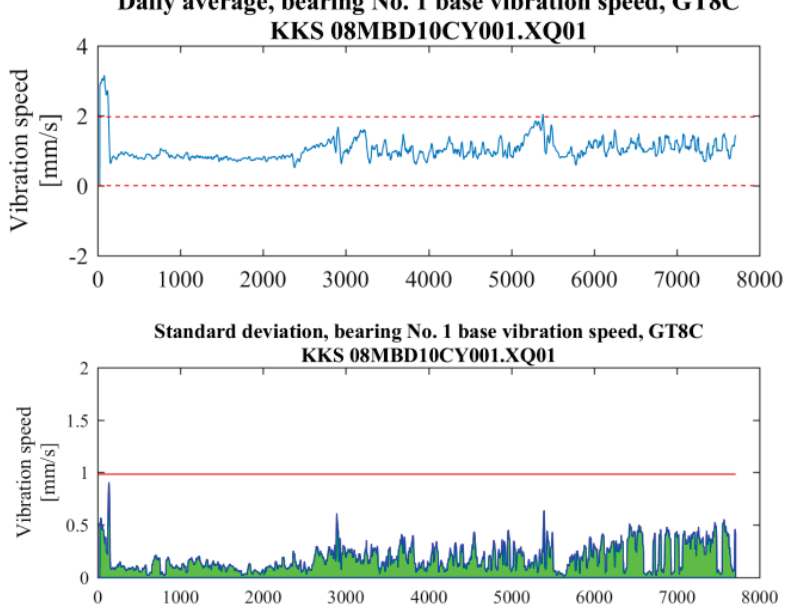

Figure 21 Daily average and standard deviation, bearing No. 1 base vibration speed, year 2011/2012_P4
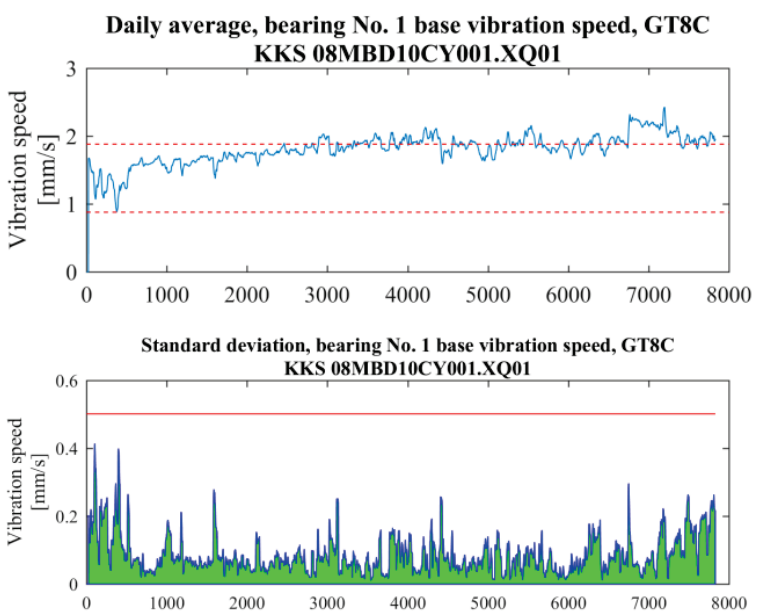

Figure 22 Daily average and standard deviation, bearing No. 1 base vibration speed, year 2012/2013_P5
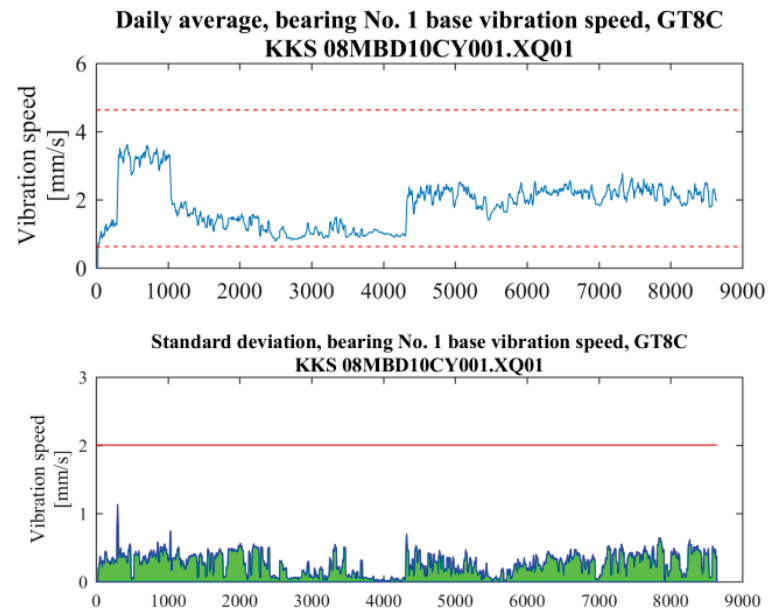

Figure 23 Daily average and standard deviation, bearing No. 1 base vibration speed, year 2013/2014_P6

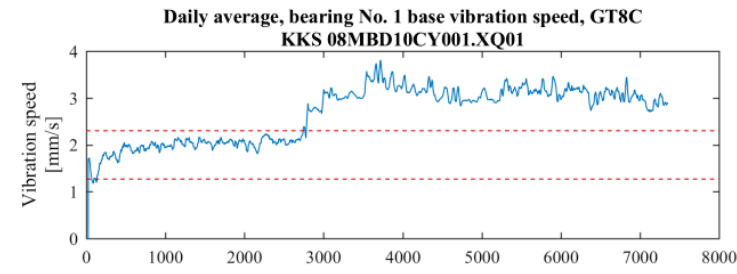

Standard deviation, bearing No. 1 base vibration speed, GT8C KKS 08MBD10CY001.XQ01

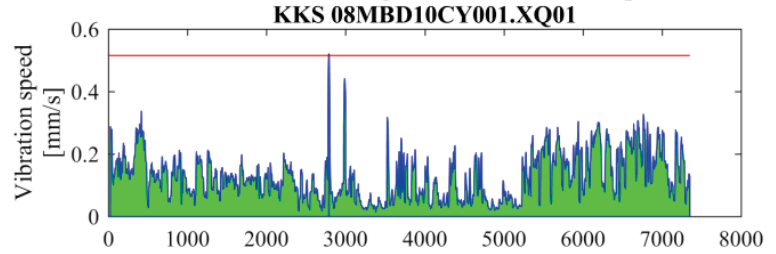

Figure 24 Daily average and standard deviation, bearing No. 1 base vibration speed, year 2014/2015_P7

The instantaneous occurrence of the abnormal state can be determined while comparing few anomalies.

The suggested method of determining abnormal states is based on basic statistical variables. The method concerned makes it possible to efficiently and effectively identify the anomalies and list the parameters for the comparison purposes. Implementation of the developed methodology in practice allows for early detection of abnormal states in the operation of the turbine.

Determining the abnormal state before the occurrence of an alarm event resulting in switching off the turbine 
gives more time for operating personnel to modify the turbine operation parameters.
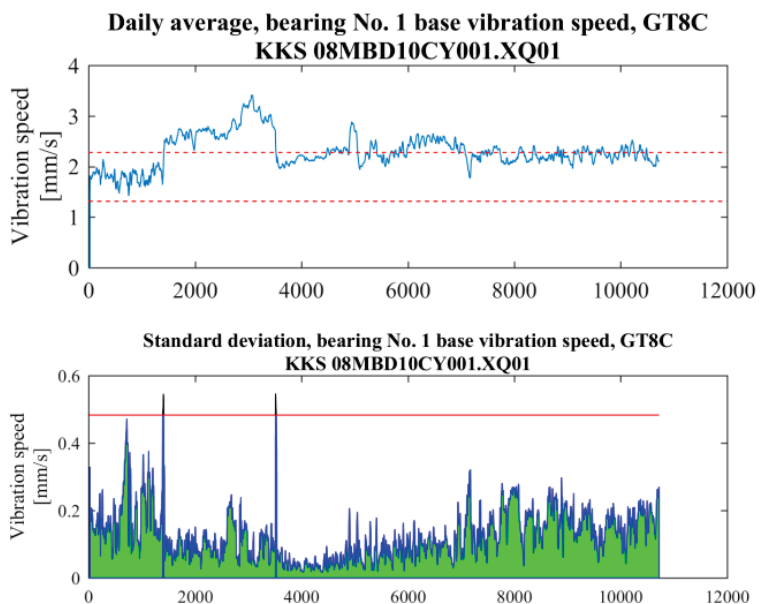

Figure 25 Daily average and standard deviation, bearing No. 1 base vibration speed, year 2015/2016_P8
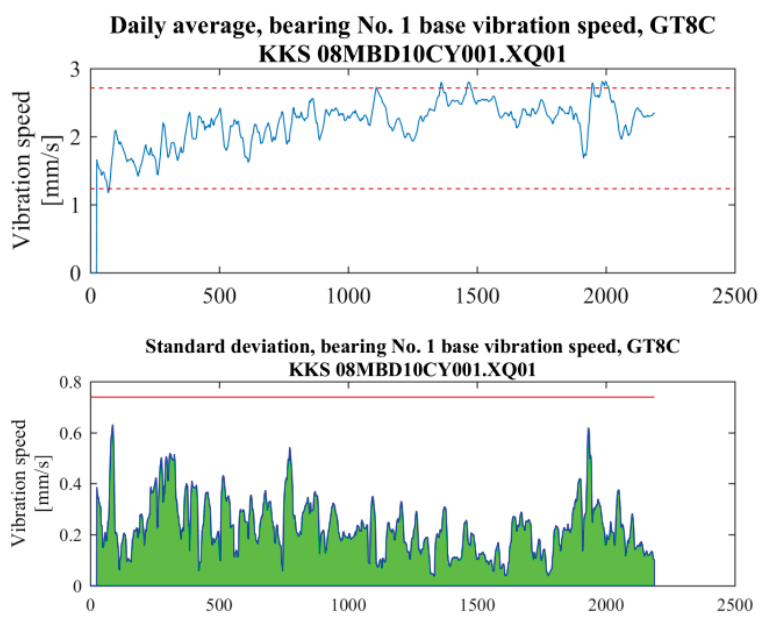

Figure 26 Daily average and standard deviation, bearing No. 1 base vibration speed, year 2016/2017_P9

\section{CONCLUSION}

The new tool, i.e. the method of determining the abnormal states shows how functions of the supervision over measured parameters of the machine can be easily implemented and supplemented.

The developed methodology for the detection of abnormal states is based on the analysis of the time domain of the extracted diagnostic signals. The inference about the correctness of course of the diagnostic signals is made on the basis of the variability analysis of these runs in the periods between turbine overhaul. The developed methodology allows it to be used by the supervision inspector to supervise the condition of the machine despite changes in the values of the diagnostic signals following subsequent turbine maintenance.

The curves provided show the daily average values in $2008-2016$ are within the range $0.5 \mathrm{~mm} / \mathrm{s}$ to $2.5 \mathrm{~mm} / \mathrm{s}$. The standard deviation was around $0.2 \mathrm{~mm} / \mathrm{s}$. The method enables the comparison of the measured parameters of the occurring event with parameters related to the similar event in the past. In a given time period the stability of parameters prevents an abnormal state to be detected by an operator or supervisor and responded to. This is very important during the continuous operation of the machine.
This allows starting the reserve machine and avoiding production losses.

The use of computer assisted methods dramatically accelerates the analysis of basic components of the measured parameters thus facilitating the possibilities of detecting the abnormal state of the machine and making a decision on the response. The added value of the presented method is its speed of use. The method can be used to determine abnormal states and the way they are detected also on other rotor machines. The use of the tool concerned would help develop the operation regime of the machine and inspection/overhaul intervals.

\section{REFERENCES}

[1] ABB Zamech Ltd. Materiały szkoleniowe, Tom 4/1.2 (1998). Filozofia dokonywania przegladów turbin gazowych produkcji $A B B$, Gorzów.

[2] Stefanowicz, K. (2014). Systemy diagnostyczne turbin przemysłowych. Wydawnictwo Naukowe Państwowej Wyższej Szkoty Zawodowej im. Jakuba z Paradyża w Gorzowie Wielkopolskim, 136-139.

[3] Stefanowicz, K. \& Bałasz, B. (2015). Budowa przemysłowych turbin gazowych - zagadnienia podstawowe. Wydawnictwo Naukowe Państwowej Wyższej Szkoły Zawodowej im. Jakuba $z$ Paradyża $w$ Gorzowie Wielkopolskim, 33-42.

[4] Gauri, S. K. (2010). Control chart pattern recognition using feature-based learning vector quantization. International Journal of Advanced Manufacturing Technology, 48, 10611073. https://doi.org/10.1007/s00170-009-2354-7

[5] Goyal, D. \& Pabla, B. S. (2015). Condition based maintenance of machine tools-A review. CIRP Journal of Manufacturing Science and Technology, 10, 24-35. https://doi.org/10.1016/j.cirpj.2015.05.004

[6] Peng, Z. \& Kessissoglou, N. (2003). An integrated approach to fault diagnosis of machinery using wear debris and vibration analysis. Wear, 255(7), 1221-1232. https://doi.org/10.1016/S0043-1648(03)00098-X

[7] Carden, E. P. \& Fanning, P. (2004). Vibration based condition monitoring: a review. Structural Health Monitoring, 3(4), 355-377. https://doi.org/10.1177/1475921704047500

[8] Montgomery, D. C. (1985). Introduction to statistical quality control. McGraw-Hill, New York.

[9] Liao, W., Wang, Y., \& Pan, E. (2012). Single-machine-based predictive maintenance model considering intelligent machinery prognostics. International Journal of Advanced Manufacturing Technology, 63, 51-63. https://doi.org/10.1007/s00170-011-3884-3

\section{Contact information:}

Konrad STEFANOWICZ, PhD candidate

(Corresponding author)

The Jacob of Paradies University (AJP)

ul. Teatralna 25, 66-400 Gorzów Wielkopolski, Poland

E-mail: kstefanowicz@ajp.edu.pl

Błażej BAŁASZ1), PhD, D. Sc. Eng.

Dariusz LIPIŃSKI2), PhD, D. Sc. Eng.

Koszalin University of Technology

ul. Racławicka 15-17, 75-620 Koszalin, Poland

1)E-mail: blazej.balasz@tu.koszalin.pl

2)E-mail: dariusz.lipinski@tu.koszalin.pl

Grzegorz WŁAŻEWSKI, PhD candidate

The Jacob of Paradies University (AJP)

ul. Teatralna 25, 66-400 Gorzów Wielkopolski, Poland

E-mail: gwlazewski@ajp.edu.pl 